\title{
Effect of the Slenderness Ratio of Piles on Ultimate Lateral Resistance in Sandy Soil
}

\author{
Iman A. Ali ${ }^{*}$, Saad F. Abbas (D), Karim H. Ibrahim \\ Civil Engineering Department,University of Technology-Iraq, Alsina'a street, 10066 Baghdad, Iraq. \\ *Corresponding author Email: 41895@ @student.uotechnology.edu.iq
}

\section{H I G H L I G H T S}

- The slenderness ratio affects the behavior of flexible piles under lateral loads.

- Relative density of sand specifies failure mode of pile under the lateral loading.

- Ultimate lateral resistance of piles affected by the density and slenderness ratio.

\section{A R T I C L E IN F O}

\begin{tabular}{l}
\hline Handling editor: Wasan I. Khalil \\
\hline Keywords: \\
Ultimate lateral resistance \\
Slenderness ratio \\
Flexible pile \\
Rigid pile \\
Relative density
\end{tabular}

\begin{abstract}
A B S T R A C T
This research presents the results of 14 tests, where the pile is subjected to static lateral loads. The tests are carried out on pile models with different length / diameter ratios embedded in sand with different relative densities. The influence of embedment length to diameter ratios (L/D), relative density and mode of failure of the pile on the ultimate lateral resistance of piles are investigated. A series of different ratios of embedded length to constant diameter ranging from 12 to 30 was used to perform this study. From the results of the experimental models, it is found that, the length to diameter ratio is a significant variable that influences the ultimate resistance of the piles, where lateral static loads were employed to the single pile by a static lateral load using a device designed for this purpose, and due to the static lateral load the pile was deflected. The ultimate lateral resistance of a pile is investigated to specify the behavior of the pile under the effect of lateral loads as a rigid or flexible pile.
\end{abstract}

\section{Introdaction}

The piles are defined as a structural member used to carry an applied load from the superstructure to a deep strong layer as well as to reinforce the soil. The embedded length of the pile depends on the magnitude of the applied load and the type of soil. Usually, the resistance of the lateral load for pile foundations is essential in the design of the structures which are undergoing earthquakes, ship impacts, high wind, movement of soil, and waves action. The vertical pile resists lateral loads or moments by deflecting laterally until the essential reaction in the surrounding soil is prepared. The lateral load piles are used to support the structures, such as high- buildings subjected to earthquakes and offshore constructions, so the behavior of laterally loaded piles is one of the main problems affected by the soil structure interaction [1]. The major objective of this research is to investigate the effect of relative density of sand on the behavior of the laterally loaded pile and to study the behavior of the pile under the effect of lateral loads and to specify a failure point in the pile.

\section{The Failure Mechanisms of Laterally Loaded Piles}

The purpose is to identify a short pile when the lateral resistance of the soil has been exceeded and reached failure. While the failure mechanization of an extremely long pile is various. Theoretically, the passive resistance to yielding provided by the soil below the yield point can be considered infinite and rotation of the pile cannot occur, where the lower part remains vertical while the upper part deforms to a shape shown in Figure $1 \mathrm{~b}$ in which failure takes place when the pile yields at the point of the maximum bending moment, and for the purpose of analysis, a plastic hinge that is able of carrying shear is assumed to develop at this point.

The failure technique of a short pile for the free headed and the fixed head condition is shown in Figure 1a and b. In the case of long (flexible) piles, failure is related, when the moment at one or more points passes the moment of resistance of 
lateral load, and the failure occurs by the generation of one or more plastic hinges along the length of the pile. The failure modes for a long pile are shown in Figure 1a. This is with a distance from the ground [2].

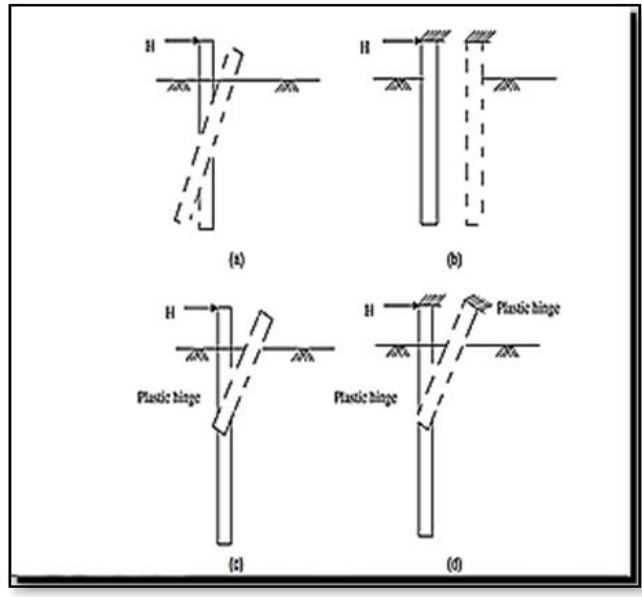

Figure 1: Modes of failure as short rigid piles and long flexible piles: (a) free headed short pile; (b) free headed- long pile

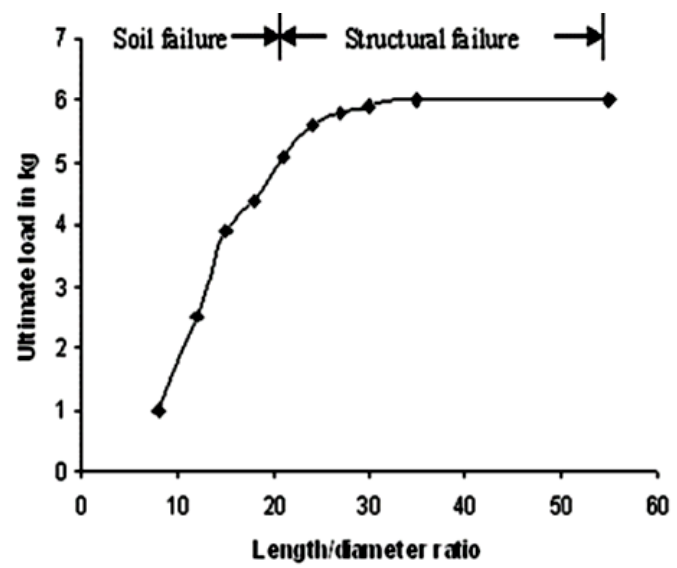

Figure 2: Specification of structural failure of the flexible pile by the length/diameter ratio versus ultimate load (Binu Sharma 2011)

\section{Analysis of Laterally Loaded Piles}

Binu Sharma (2011) studied a method to determine whether a pile behaves as rigid or as flexible, where he suggested a procedure to specify the flexible pile by studying the change of ultimate lateral load with the length/diameter ratio of the piles as shown in Figure 2.6 [3].

However, the failure mechanism is observed to be influenced by relative density of the sand bed. Transition from rigid pile to flexible pile happened at L/D ratio between " 21 to 24 " at relative density of $30 \%$ ", whereas at relative density of $50 \%$ and $80 \%$ it occurred at L/D ratio between "18 to 21 " and between "12 to15", respectively. As relative density increases, the probability of structural failure occurs as shown in Figure 2.

The following equation is used to calculate the ultimate lateral load for floating piles. This analysis is based on the limit analysis theory proposed according to [4].

$$
\mathrm{Hu}=\frac{0.5 \gamma \mathrm{BL}^{3} \mathrm{Kp}}{L+e}
$$

Where: $\mathrm{Hu}=$ Ultimate lateral load,

$\gamma=$ Dry unit weight of sand,

$\mathrm{L}=$ Embedded length, and

$\mathrm{B}=$ Pile width or diameter.

$\mathrm{e}=$ Distance from horizontal applied load at the pile to ground surface, and

$\mathrm{Kp}=\tan ^{2}(45+\emptyset / 2)$, where $\varphi$ is the internal friction angle of the soil [4].

\section{Experimental Work}

In this study, two groups of tests are carried out to investigate the behavior of pile-soil interaction under lateral loading to specify the flexible pile. The first group: Seven single piles were installed within a loose state with an RD=30\%. The second group: seven single piles were embedded within a medium state with an $\mathrm{RD}=50 \%$.

\section{Material Properties}

1. Sand Characterization: The soil samples used in this study are brought from Karbala city, Iraq. The grain size distribution of the soil used is displayed in Figure (3). The standard tests are conducted to determine the physical and mechanical properties of the soil type. The soil is classified as well graded sand (SP) according to (USCS). Table (1) summarizes the physical properties of the tested sand.

2. Model of Pipe Piles: In this study, 14 models of steel pipe pile with a diameter of $(20 \mathrm{~mm})$, wall thickness $0.5 \mathrm{~mm}$ and different lengths of piles of $(360,420,480,540,600,660$ and 720) $\mathrm{mm}$ are used to perform the physical models (see, Plate 1). The ratio of the length/diameter (L/D) of the piles is used as suggested by Sharma (2011), which is varied between (12 $-30)$.

3. The Set-up of the Experimental Model: A device of the experimental model is shown in Plate 2 and Figure 4. A cube steel container with dimensions of $(750 \times 750 \times 750) \mathrm{mm}$ is used. The lateral loading system includes a horizontal hydraulic jack system and we modified it with $(15 \mathrm{~mm})$ loading screw steel shaft that employs a lateral force which is applied on the 
pile cap by using a sharpen shaft that gives the ability to provide a point load, and the shaft is attached with a load cell and it is an indicator to measure the load applied from the jack, where this load cell is joined between the loading steel shaft (that is united with the hydraulic jack) and the sharpen shaft attached with piles head as in Plate 3 a and c).

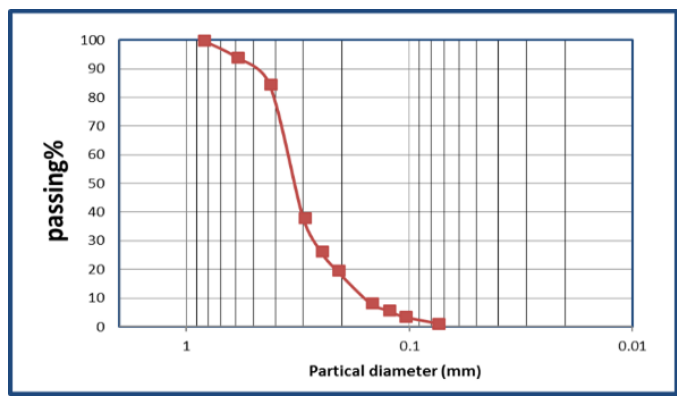

Figure 3: The grains size distribution curve

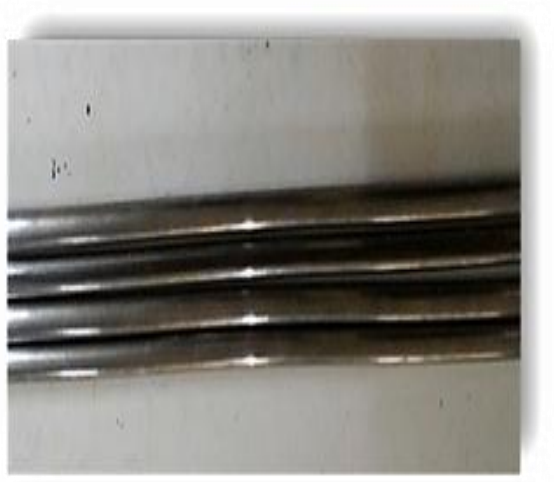

Plate 1: The model of piles

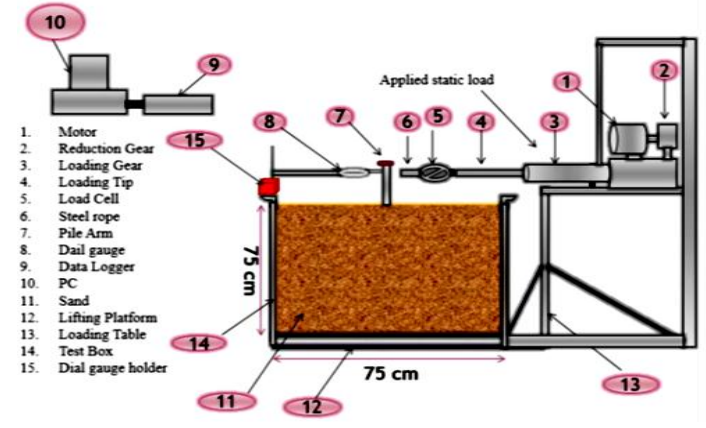

Figure 4: The general layout of the experimental model

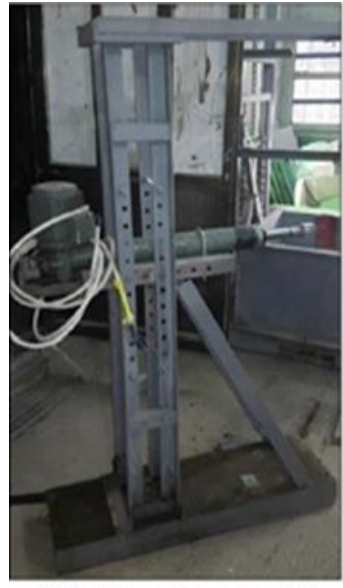

(a) The structure of power screw jack

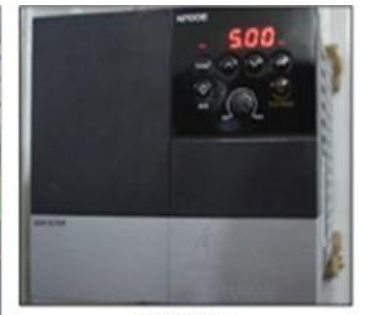

(b) AC drive

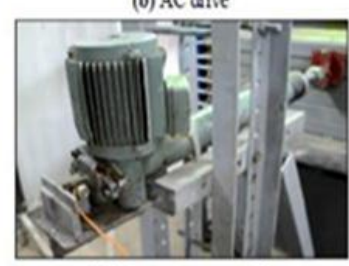

(c) The power screw jack
Plate 2: (a) Frame holding hydraulic jack, (b) AC drive and (c) hydraulic jack

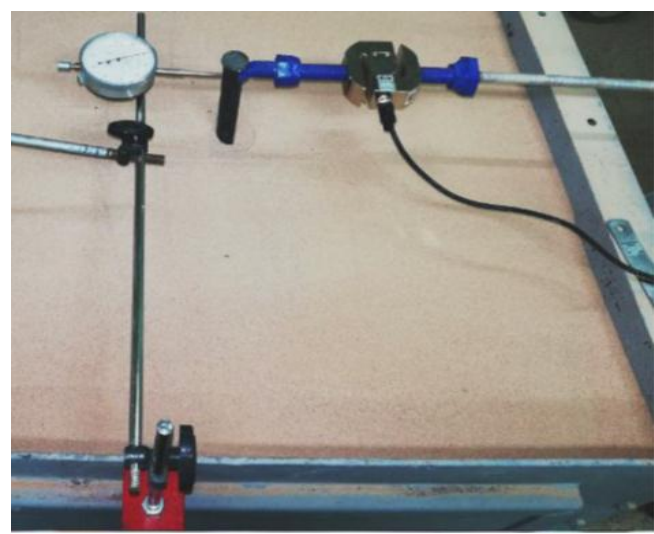

Plate 3: The dial gauge used to measure the lateral displacement of Pile 6.

The Ultimate Lateral Resistance of Piles

The hydraulic jack is programmed to move with a rate of changes from a very slow movement to a moderate movement rate where we can input it manually from the "AC" system to obtain an appropriate rate of movement. The hydraulic jack system firstly consists of "a control device to change the speed rate (AC derive) cylinder and an electric jack". The structure of the hydraulic jack is designed so that it moves up and goes down along the shaft structure that carries the jack so that many 
levels can be obtained using the same loading. The electrical device is (AC Inverter from Hyundai Company). It is used to measure the speed rate from (5 -100) $\mathrm{mm} / \mathrm{min}$. This device has been manufactured by Elewi, A. S. (2017) [9].

4. Dial gauge: A dial gauge is used to measure the displacement of the pile as in Plate 3.

\section{Results and Discussion}

Behavior of Soil-Pile System under Lateral Loading: The ultimate lateral loading should be defined to explain the results of a laterally loaded single pile. In this research, the behavior of the pile is studied as short or long. The first stage, the design of lateral load, is calculated by using the equation given by Davis and Poulos (1980) as explained in Chapter Two. Then, the incrimination of lateral load is applied at a very low rate that equals to $(0.50) \mathrm{mm} / \mathrm{min}$ and we allow the pile to reach an equilibrium state at each level of lateral loading. The tests were performed according to the specifications of (Standard Test Methods for Deep Foundations under Lateral Load of ASTM D3966 - 07).

The loading procedure is performed by applying the total load in 10 steps up to 200 percent of the design load calculated by the equation of Poulos and Davis (1980), where the loads is applied in increments of $25 \%$ of the working load until reaching the ultimate lateral load (i.e., 25 percent, 50 percent, 75 percent, 100 percent 125 percent, 150 percent, 170 percent, 180 percent 190 percent, and 200 percent). The applied lateral load, displacement of pile at the ground surface and pile head deflection are recorded. Figures 5 to 11 show the lateral loads-displacement of piles with different length/diameter ratios embedded in loose sand with a relative density of (RD=30\%).

Figures (12 to 18 ) show the ultimate lateral load of piles with different length/diameter ratios embedded in medium sand with a relative density of $(\mathrm{RD}=50 \%)$.

From the results of lateral loads-displacement curves shown in Figures (5-18), it can be seen that by an increase in (L/D) ratio the lateral loads of each pile increased in whole specific relative densities.

Due to that, the ultimate resistance of piles for a same L/D ratio increases with an increase in relative density.

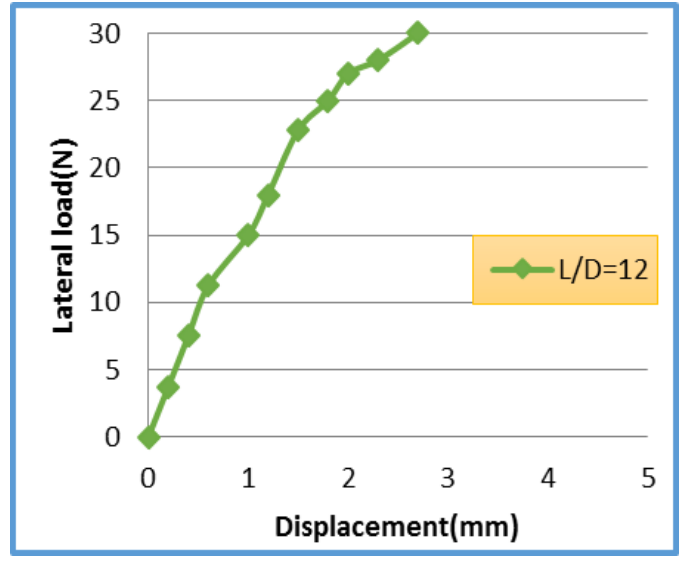

Figure 5: Lateral loads-displacement curve of pile in sand with relative density of $30 \%$

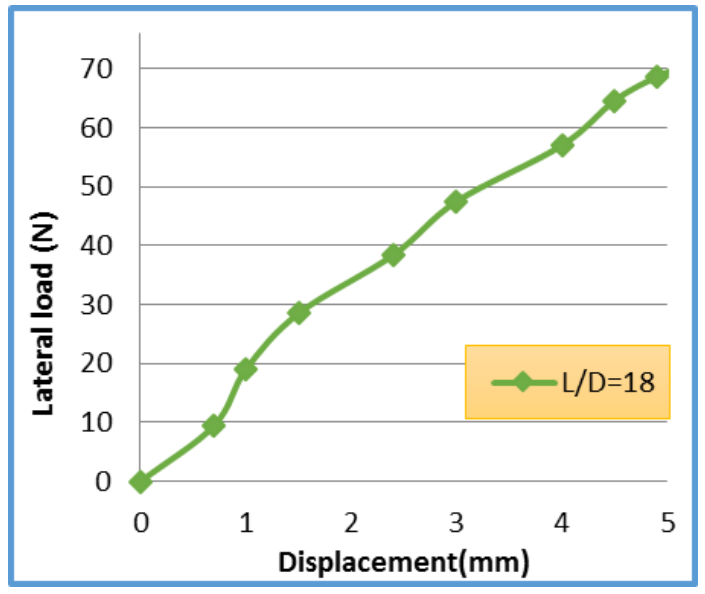

Figure 7: Lateral loads-displacement curve of pile in sand with relative density of $30 \%$

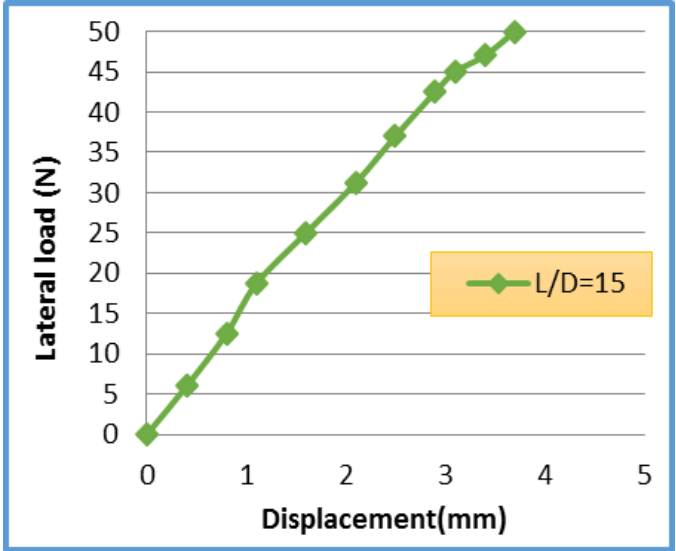

Figure 6: Lateral loads-displacement curve of pile in sand with relative density of $30 \%$

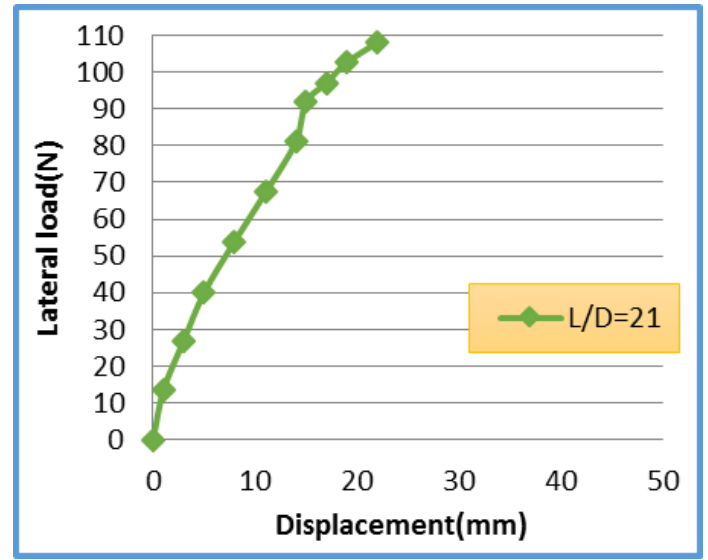

Figure 8: Lateral loads-displacement curve of pile in sand with relative density of $30 \%$ 


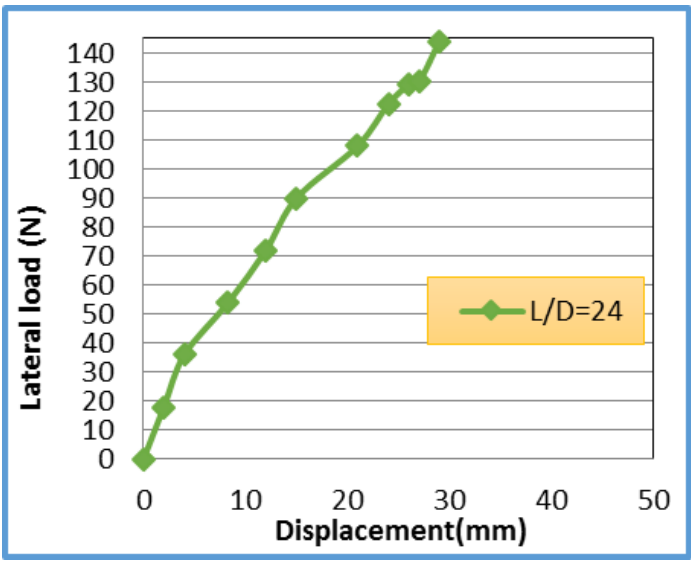

Figure 9: Lateral loads-displacement curve of pile in sand with relative density of $30 \%$

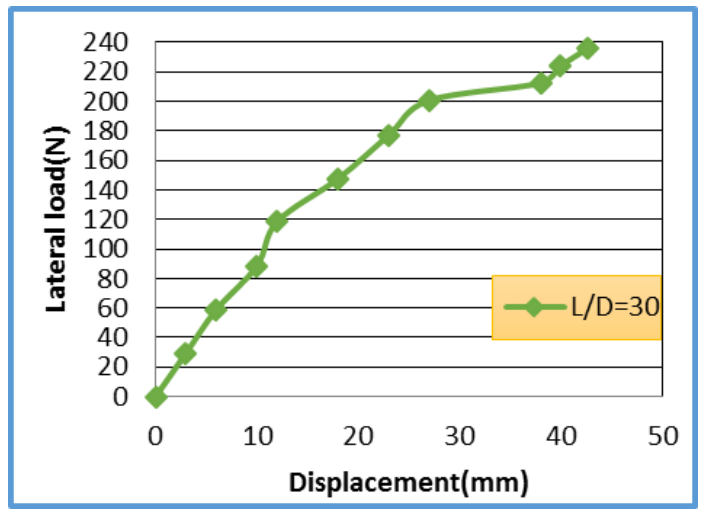

Figure 11: Lateral loads-displacement curve of pile in sand with relative density of $30 \%$

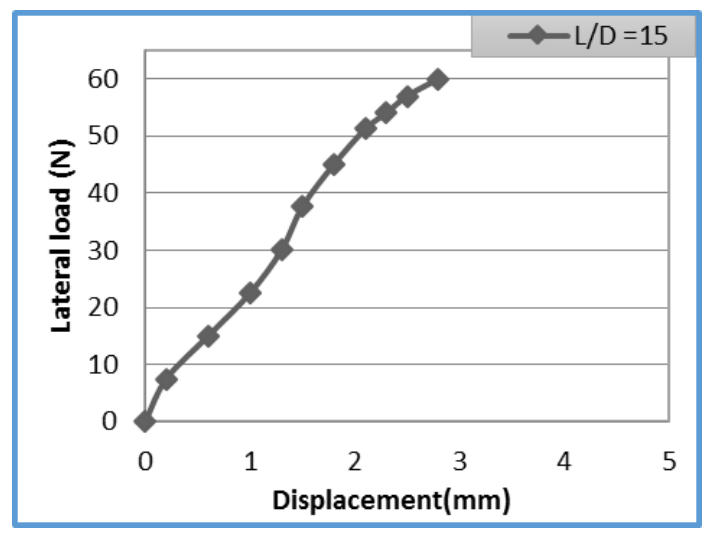

Figure 13: Lateral loads-displacement curve of pile in sand with relative density of $50 \%$

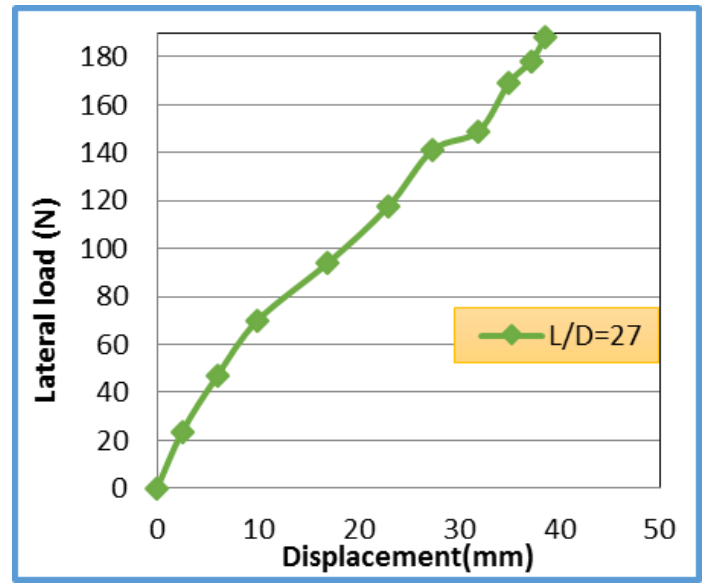

Figure 10: Lateral loads-displacement curve of pile in sand with relative density of $30 \%$

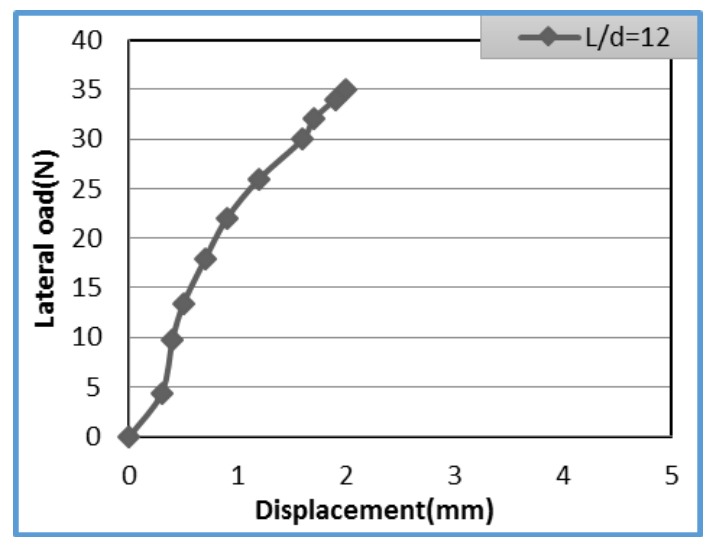

Figure 12: Lateral loads-displacement curve of pile in sand with relative density of $50 \%$

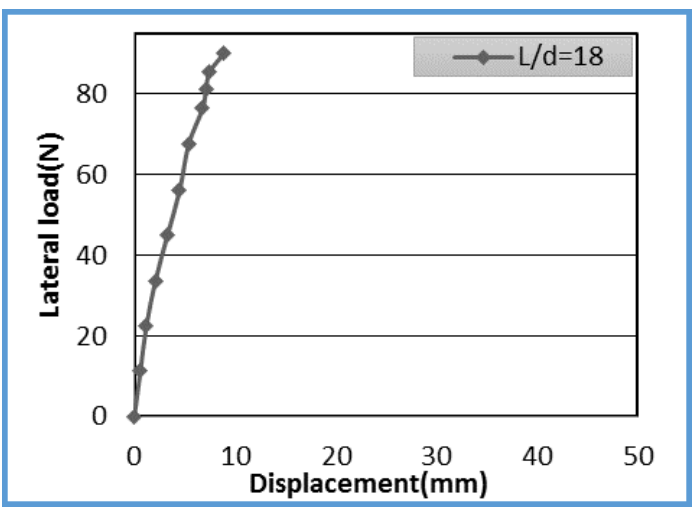

Figure 14: Lateral loads-displacement curve of pile in sand with relative density of $50 \%$ 


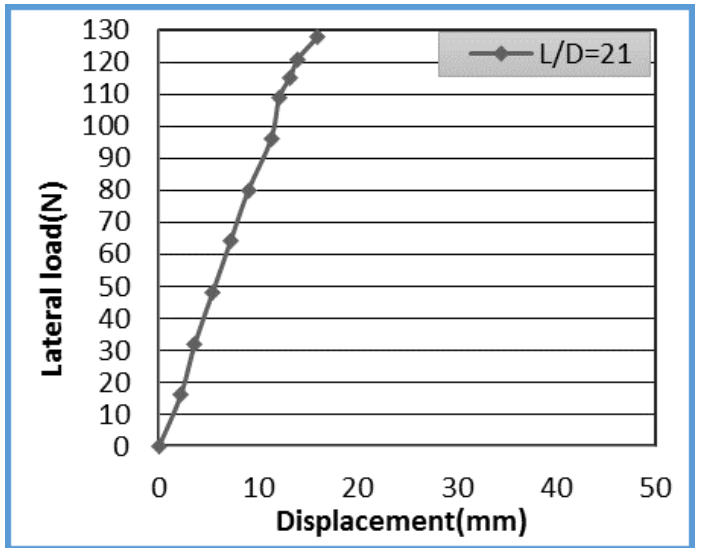

Figure 15: Lateral loads-displacement curve of pile in sand with relative density of $50 \%$

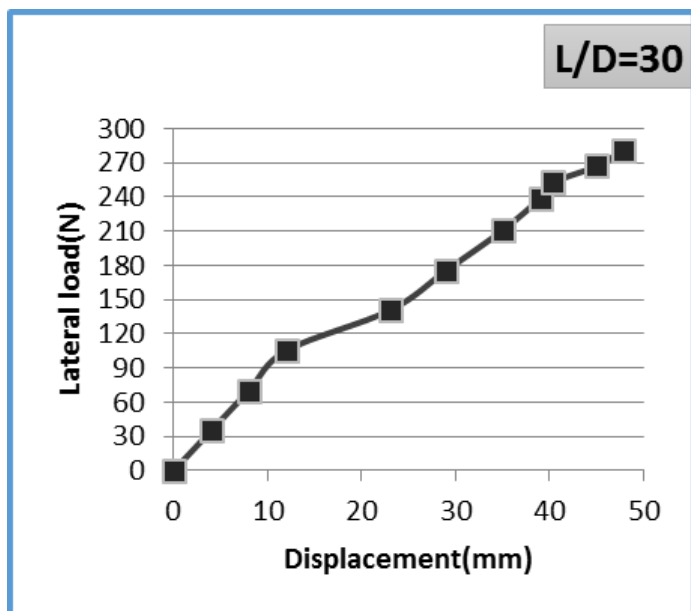

Figure 17: Lateral loads-displacement curve of pile in sand with relative density of $50 \%$

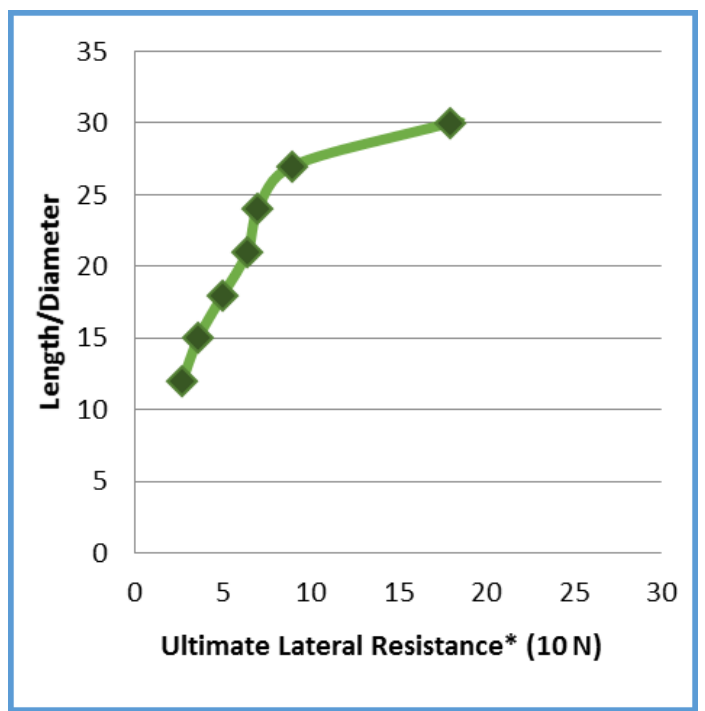

Figure 19: The length/diameter ratio versus ultimate lateral resistance at relative density of $30 \%$

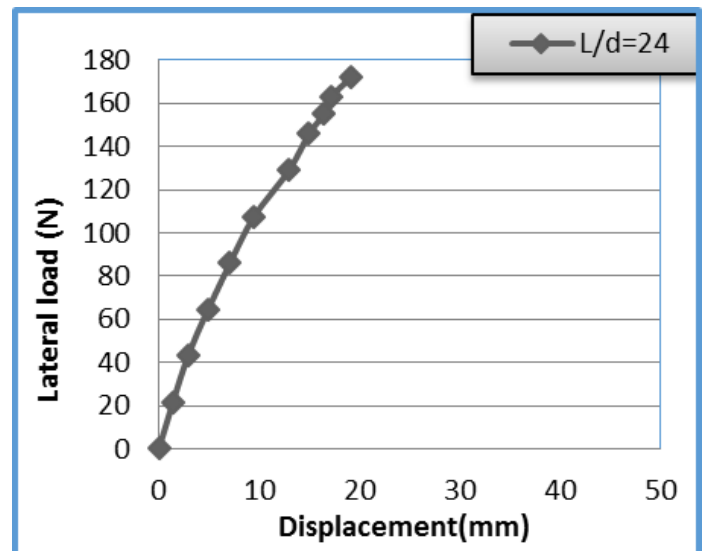

Figure 16: Lateral loads-displacement curve of pile in sand with relative density of $50 \%$

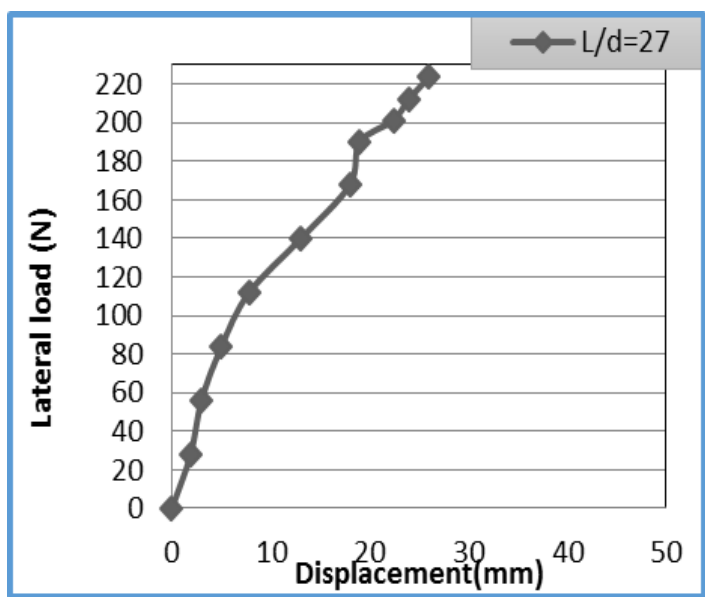

Figure 18: Lateral loads-displacement curve of pile in sand with relative density of $50 \%$

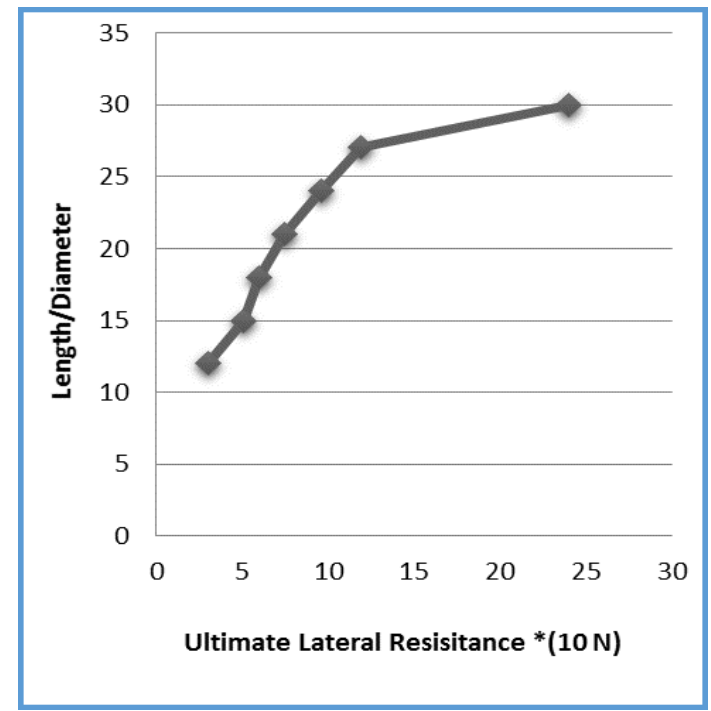

Figure 20: The length/diameter ratio versus ultimate lateral resistance at relative density of $50 \%$ 


\section{Effect of Lateral Loading on the Pile with the mode of failure}

In this study, the failure of pile under lateral load is specified as the point on the ultimate lateral resistance against the lateral loads - displacement curve, "the curve stays continuous with displacement increase without an extra increase in the lateral load". The ultimate lateral resistances of pile are obtained from load-displacement curves by these following criteria:

1. A single tangent method.

2. A double tangent method.

3. The load corresponding to line displacement equals to $10 \%$ pile diameter.

Broms (1964a) in his investigation about the lateral loads piles in the cohesion less soil, considered two types of failure of piles. The first is a failure of soil and the other is the crack of piles by a forming of plastic hinge or structural failure in the body of the pile. It can be observed that the first type is a short pile. A short pile on application of lateral load rotates and passive resistance is developed near the ground surface at the opposite face.

Failure occurs at the toe when the passive resistance at the head and toe are exceeded. In the case of a long pile, where it is noticed that the accumulative passive resistance that is formed at the lower portion of the pile is very high and because that a pile cannot rotate, where the failure happens in the point of a maximum bending moment. Figures (19) and (20) show the variation of ultimate lateral load resistance of pile with different ratios of length/diameter of the pile at the two different relative densities. The figures clearly show the effect of relative density on the ultimate lateral resistance, where, the rate of increase in the ultimate lateral resistance is linear up to L/D 24 and 21 for the pile embedded in loose and medium sand, respectively. After that, the relationship is non-linear indicating that the failure occurred in the pile, therefore; the pile is behaving as a flexible pile [10].

\section{Conclusions}

The following conclusions can be drawn from the study:

1. The ultimate lateral resistance is affected by the density of sand, where it is increased by increasing the density.

2. The ultimate lateral resistance is affected by the length to diameter ratio of the pile where it increases by increasing the ratio of "length/ diameter" (L/D).

3. The pile under the influence of lateral loads behaves as a rigid pile when the (L/D) is greater than 24 which is embedded in the sand with a density of $(\mathrm{RD}=30 \%)$.

4. The pile under the influence of lateral loads behaves as a flexible pile when the (L/D) is greater than 21 which is embedded in the sand with a density of $(\mathrm{RD}=50 \%)$.

Author contribution Funding

All authors contributed equally to this work.

This research received no specific grant from any funding agency in the public, commercial, or not-for-profit sectors. Data availability statement

The data that support the findings of this study are available on request from the corresponding author.

\section{Conflicts of interest}

The authors declare that there is no conflict of interest.

\section{References}

[1] S. J. Al Mandeel, Behavior of Laterally Loaded Pile Group Model in Sand. M.Sc. Thesis, Dahran, Saudia Arabia: King Fahd University of Petroleum \& Minerals, (2000). Available:

[2] https://core.ac.uk/download/pdf/12098572.pdf

[3] M. Tomlinson, and J. Woodward, Pile design and Construction Practice. published by Taylor \& Francis. Fifth edition, (2015). Available: https://menglim498.files.wordpress.com/2013/04/pile-design-and-construction.pdf

[4] B. Sharma ,A Model Study of Micropiles subjected to Lateral Loading and Oblique Pull. Indian Geotechnical Journal, 41(4), https://scholar.google.com/scholar?cluster $=7017339811039024559 \& h l=a r \& a s \_s d t=0,5 \&$ sciodt $=0,5$ 196-205(2011).Available:

[5] E.H. Davis and H.G Poulos "Pile Foundation Analysis and Design", New York:Wiley,(1980).Available: https://catalogue.nla.gov.au/Record/2877390

[6] ASTM D3080-2003, "Standard Test Method for Direct Shear Test of Soils under Consolidated Drained Conditions", American Society for Testing and Materials.Available: https://standards.globalspec.com/std/49278/astm-d3080

[7] ASTM D2487-11, 2011. "Standard Practice for Classification of Soils for Engineering Purposes", West Conshohocken: American Society for Testing and Materials. Available: https://www.astm.org/DATABASE.CART/HISTORICAL/D248711.htm 
[8] ASTM D4254-2000, "Standard Test Method for Minimum Index Density and Unit Weight of Soils and Calculation of Relative Density", American Society for Testing and Materials. Available: https://standards.globalspec.com/std/9996935/ASTM\%20D4254

[9] ASTM D4253- $00 \quad$ (2006), West Conshohocken, Pennsylvania, USA. Available: https://www.astm.org/DATABASE.CART/HISTORICAL/D4253-00R06.htm

[10] A. S. Elewi, Response of Single Pile and Pile Groups to Lateral Sandy Soil Movement. PhD. Thesis, University Of Technology: Building and Construction Engineering Department, Iraq, (2017).

[11] B.B. Broms, Lateral Resistance of Piles in Cohesionless Soils. J.S.M.F.D., Asce, [Online],Vol. 90, Sm3: 123156,(1964)a.Available: https://cedb.asce.org/CEDBsearch/record.jsp?dockey=0013415.

Apendix:

\section{A.1 the theoretical side by evaluation applied lateral loaded and displacement}

Table (A-1): Applied lateral loaded and displacement in loose sand for one pile

\begin{tabular}{lccc}
\hline \multicolumn{1}{c}{ Design Load } & min Load & Load Duration & Displacement \\
\hline 0 & 0 & 0 & 0 \\
25 & 10 & 29.5 & 3 \\
50 & 10 & 59 & 6 \\
75 & 15 & 88.5 & 10 \\
100 & 20 & 118.5 & 12 \\
125 & 20 & 147.5 & 18 \\
150 & 20 & 177 & 23 \\
170 & 20 & 200.6 & 27 \\
180 & 20 & 212.4 & 36 \\
190 & 20 & 224 & 38 \\
200 & 60 & 236 & 39 \\
& & & \\
\hline
\end{tabular}

Table (A-2): Applied lateral loaded and displacement in medium sand for one pile

\begin{tabular}{lccc}
\hline Design Load, \% & Load Duration, min & Load & Displacement \\
\hline 0 & 0 & 0 & 0 \\
25 & 10 & 35.15 & 4 \\
50 & 10 & 70.3 & 8 \\
75 & 15 & 105.4 & 12 \\
100 & 20 & 140.6 & 23 \\
125 & 20 & 175.7 & 29 \\
150 & 20 & 210.9 & 35 \\
170 & 20 & 239 & 39 \\
180 & 20 & 253 & 40.0 \\
190 & 20 & 267 & 45 \\
200 & 60 & 281.2 & 47.8 \\
\hline
\end{tabular}

